Article

\title{
Does Shrub Encroachment Indicate Ecosystem Degradation? A Perspective Based on the Spatial Patterns of Woody Plants in a Temperate Savanna-Like Ecosystem of Inner Mongolia, China
}

\author{
Xiao Wang ${ }^{1}$, Lina Jiang ${ }^{2}$, Xiaohui Yang ${ }^{3}$, Zhongjie Shi ${ }^{3, *}$ and Pengtao Yu $^{1}$ \\ 1 Key Laboratory of Forest Ecology and Environment of the State Forestry Administration of China, \\ Research Institute of Forest Ecology, Environment and Protection, Chinese Academy of Forestry, \\ Beijing 100091, China; wangxiao@caf.ac.cn (X.W.); yupt@caf.ac.cn (P.Y.) \\ 2 Research Institute of Forestry New Technology, Chinese Academy of Forestry, Beijing 100091, China; \\ jianglina@caf.ac.cn \\ 3 Institute of Desertification Studies, Chinese Academy of Forestry, Beijing 100091, China; yangxh@caf.ac.cn \\ * Correspondence: shizj@caf.ac.cn; Tel.: +86-10-6282-4106
}

Received: 7 October 2020; Accepted: 23 November 2020; Published: 25 November 2020

\begin{abstract}
Shrub encroachment, i.e., shrub emergence or an increase in woody plant cover, has been widely observed in arid and semiarid grasslands and savannas worldwide since the 2000s. However, until now, there has been a clear division of opinion regarding its ecological implications. One view is that shrub encroachment is an indicator of ecological degradation, and the other is that shrub encroachment is a sign of the restoration of degraded ecosystems. This division leads to completely different judgments about the states and transition phases of shrub-encroached ecosystems, which further affects decisions about their conservation and management. To determine whether ecosystems experiencing shrub encroachment are degrading or are in a postdegraded restoration stage, the spatial distributions and interactions of woody plants after shrub encroachment were investigated in this study. An Ulmus pumila-dominated temperate savanna-like ecosystem with significant shrub encroachment in the Otindag Sandy Land, Inner Mongolia, China, was selected as the research area, and woody plants were surveyed within a 25-hectare $(500 \times 500 \mathrm{~m})$ plot. Spatial point pattern analysis was employed to analyze the distribution patterns of the woody plants. The results indicated different patterns for $U$. pumila trees, i.e., a random distribution pattern for old trees (with a diameter at breast height $(\mathrm{DBH})$ of more than $20 \mathrm{~cm}$ ) and aggregated distribution patterns for medium $(5 \mathrm{~cm} \leq \mathrm{DBH}<20 \mathrm{~cm}$ ) and juvenile trees (DBH $<5 \mathrm{~cm})$ at scales of $0-9$ and $0-12 \mathrm{~m}$, respectively. For most shrubs, there was significant aggregation at a scale of $0-6 \mathrm{~m}$. However, there were significant negative relationships between old $U$. pumila trees $(\mathrm{DBH} \geq 20 \mathrm{~cm})$ and most shrub species, such as Caragana microphylla and Spiraea aquilegifolia. In contrast, there were positive relationships between juvenile trees $(\mathrm{DBH}<5 \mathrm{~cm}$ ) and most shrub species. These results suggest that, to some extent, shrub encroachment may have disrupted the normal succession pattern in the $U$. pumila community in this area, and without conservation, the original tree-dominated temperate savanna-like ecosystem may continue to deteriorate and eventually become a shrub-dominated temperate savanna-like ecosystem.
\end{abstract}

Keywords: shrub encroachment; spatial pattern; temperate savanna; ecosystem degradation

\section{Introduction}

Shrub encroachment in grasslands and the densification of woody plant cover in savannas have been widely documented across many arid and semiarid areas of the world [1-4], including in 
South America, Australia, and the warm deserts of the Southwestern United States. However, until now, there has been a clear division of opinion about its ecological indication. One view is that shrub encroachment is an indicator of land degradation that is often associated with ecosystem degradation [5], such as declines in forage productivity, biodiversity, and socioeconomic potential, as well as increased erosion [6]. However, an alternative viewpoint proposing that shrub emergence is a sign of the restoration of degraded ecosystems has emerged recently [7,8], considered to support the biodiversity and a variety of ecosystem services [9]. In addition, shrub encroachment has been described as an alternative stable state occurring several times during the last two millennia in African savannas [10]. Some studies also found that the role of shrub species was important in the rehabilitation of degraded sandy land ecosystems [11]. Furthermore, different opinions exist as to the causes of shrub encroachment in different types of ecosystems [12]: some studies found that underuse leads to shrub and subsequent tree encroachment and, finally, conversion to forest [12]; however, overgrazing usually causes shrub encroachment in Africa and the Mongolia Plateau [10]. This difference in the perception of shrub encroachment could lead to completely different judgments of the states and transitions of shrub-encroached ecosystems, which would further affect decisions about their conservation and management [13]. An innovative study [14], combined with the landscape history and other environmental factors, quantified the process and indicative significance of shrub encroachment and provided us with new ideas. Therefore, more attention needs to be paid to ecosystem changes after shrub encroachment to clarify their ecological significance, especially the significance of the degree of shrub encroachment and changes in distribution patterns and structure. This information could then be used to quantify the ecological indications of shrub encroachment.

As a common tree species distributed widely throughout the forest-steppe ecotone on the Mongolian Plateau [15,16], Ulmus pumila forms a stable savanna-like woody-herbaceous complex ecosystem in association with grass in the Horqin Sandy Land, the Otindag Sandy Land, and the Hulunbuir Sandy Land in Northern China [17,18]. The sparse U. pumila trees on the temperate savanna-like ecosystem have ecological significance because they provide sand stabilization and also resting places for livestock [19]. In recent years, due to various changing conditions, such as climate change and land use change in the course of economic development [20-22], there has been severe damage to the $U$. pumila-dominated temperate savanna-like ecosystem. This damage has led to an increase in the number of shrubs and the densification of woody plant cover as well as outcomes such as decreasing temperate savanna-like ecosystem area, the loss of structural integrity, poor population regeneration, and changing spatial patterns [23,24]. Previous studies have focused mainly on the vegetation distribution, possible encroachment mechanisms, vegetation characteristics, species composition, and carbon budget in the $U$. pumila-dominated temperate savanna-like ecosystem after shrub encroachment $[25,26]$. It was found that shrub coverage in the grasslands of Inner Mongolia reached $12.8 \%$ and that the emergence of Caragana microphylla was an indicator of grassland degradation in Inner Mongolia [27]. However, the spatial patterns of woody plants and their interrelationships associated with shrub encroachment are often overlooked despite having important effects on ecosystem functions [28].

Spatial pattern analysis is an important method for studying the distribution and relationships of different plants [29,30]. The spatial patterns of species and the spatial relationships among species significantly impact growth, reproduction, death, resource utilization, and gap formation among species [31,32]. The analysis of a species' spatial pattern helps us to understand both the ecological processes that form the pattern (such as intra- and interspecific competition, interference, and environmental heterogeneity) and the ecophysiological traits of the plant species, including the relationships between these plants and their environment [33,34]. Recently, a spatial pattern analysis method has been used to clarify the vegetation degradation processes underlying the patterns of individual species in semiarid and arid areas [35,36].

In this study, our objective is to explore how shrub encroachment affects the spatial distribution and interaction of woody plants in a temperate savanna-like ecosystem. We hypothesize that there are 
differences in the relationships between $U$. pumila trees of different DBHs and shrubs. The following questions will be addressed: (1) What are the distribution patterns of $U$. pumila trees and shrubs in a temperate savanna-like ecosystem? (2) What are the interspecific interactions between $U$. pumila trees and shrubs? and (3) Do tree-shrub spatial associations change as a function of tree size?

\section{Materials and Methods}

\subsection{Study Area}

U. pumila-dominated temperate savanna-like ecosystem, which is distributed widely throughout the forest-steppe ecotone on the Mongolian Plateau, China, is quite different from North American prairies and African savannas in terms of climate, soils, and dominant plant functional types; however, there are some taxonomical similarities among these ecosystems at the genus and family levels [37,38]. The study area experiences a typical temperate continental semiarid climate, with warm summers and cold winters. The mean annual precipitation is approximately $350 \mathrm{~mm}, 70 \%$ of which occurs from June to August. The mean annual pan evaporation is $1900 \mathrm{~mm}$. The mean annual air temperature is $1.6^{\circ} \mathrm{C}$, with a maximum monthly temperature of $17.8^{\circ} \mathrm{C}$ (July) and a minimum monthly temperature of $-17.6^{\circ} \mathrm{C}$ (January) [37,38]. The main soil types are aeolian sandy soils with a mean thickness of $200 \mathrm{~cm}$ and a calcic horizon occurring at $30-100 \mathrm{~cm}$ depth. In this forest-steppe ecotone, U. pumila is dominant; the other species that occur include other woody species, including C. microphylla, Spiraea aquilegifolia, Ribes diacanthum and Salix linearistipularis, and herbaceous plants, including Leymus chinense and Cleistogenes squarrosa [39]. The main land use in the area is grazing, and the livestock are primarily cattle. The local herders have implemented alternating seasonal grazing (winter and spring) and mowing (autumn) regimes since 2000 [40]; before that time, annual grazing was the local practice. Shrub encroachment, such as the spread of $C$. microphylla, has been clearly observed in grasslands and savannas in this area, resulting in a landscape characterized by a mosaic of shrub and grass patches.

\subsection{Research Site and Data Collection}

Most work about the spatial distribution and interaction of woody plants had been done in single hectare or smaller plots, but the relative rarity of many species in forests necessitated large-scale census plots. Thus, plots usually with more than 5 hectares, named large plots, are considered as representative of local vegetation, which could cover the local typical vegetation and topography in a region. By a large plot, the interference of scale and environmental heterogeneity could be avoided for the study on vegetation composition, pattern, and biodiversity [41]. This method has been widely used in global forest dynamic monitoring.

In this study, this large plot method was applied and one large plot with an area of 25 ha $(500 \mathrm{~m} \times 500 \mathrm{~m})$ was established following the plot standards of the Center for Tropical Forest Science (CTFS) network [41]. It was located in the Otindag Sandy Land in Inner Mongolia, China $\left(115^{\circ} 16^{\prime} \mathrm{E}\right.$, $42^{\circ} 50^{\prime} \mathrm{N}$ ), in a typical area of Ulmus pumila-dominated temperate savanna-like ecosystem (Figure 1).

Then, this large plot was further divided into 625 subplots $(20 \mathrm{~m} \times 20 \mathrm{~m})$. All free-standing trees with stem diameters at breast height (DBHs) of more than one centimeter and all shrubs were tagged, mapped, and identified to species during the summer of 2013-2014. The coordinates of woody plants in each subplot were recorded using an Electronic Total Station, with the southwestern corner of the subplot as the origin. Additionally, in the center of each subplot, a small plot with the size of $1 \times 1 \mathrm{~m}$ was setup. All herbaceous species were identified and their cover ratios and numbers were recorded.

All U. pumila trees were classified into three categories according to their DBH [42], namely, old trees $(\mathrm{DBH} \geq 20 \mathrm{~cm})$, medium trees $(5 \mathrm{~cm} \leq \mathrm{DBH}<20 \mathrm{~cm})$, and juvenile trees $(\mathrm{DBH}<5 \mathrm{~cm})$ (Table 1). 


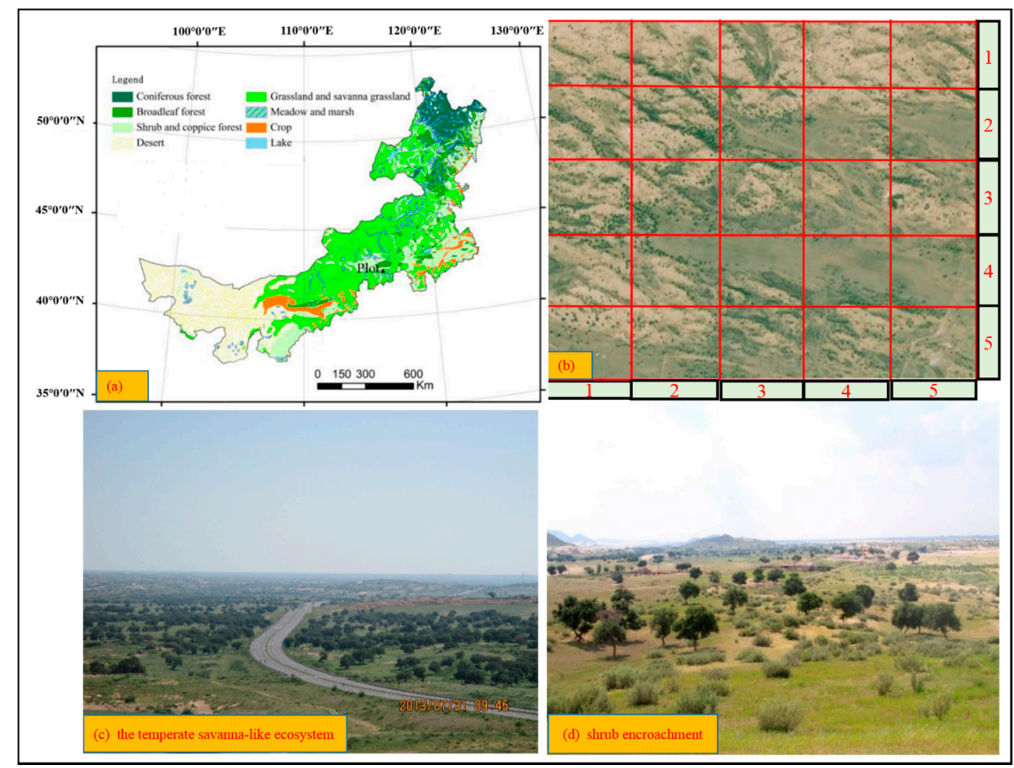

Figure 1. Map of the Otindag Sandy Land and the location of the study region (a) location; (b) sample map; (c,d) pictures of the landscape.

Table 1. Basic parameters of U. pumila trees and shrubs.

\begin{tabular}{|c|c|c|c|c|c|}
\hline Species & Category & Number & $\begin{array}{l}\text { Height } \\
\text { (m) }\end{array}$ & $\begin{array}{l}\text { Maximum } \\
\text { Crown } \\
\text { Radius (m) }\end{array}$ & $\begin{array}{c}\text { Minimum } \\
\text { Crown Radius } \\
(\mathrm{m})\end{array}$ \\
\hline \multirow{3}{*}{ U. pumila trees } & Old & 750 & $8.4 \pm 0.94$ & $6.2 \pm 0.83$ & $5.0 \pm 1.53$ \\
\hline & Medium & 250 & $5.3 \pm 0.93$ & $4.1 \pm 0.25$ & $3.2 \pm 1.27$ \\
\hline & Juvenile & 400 & $1.7 \pm 0.30$ & $1.5 \pm 0.30$ & $0.4 \pm 0.22$ \\
\hline \multirow{8}{*}{ Shrubs } & Salix linearistipularis & 292 & $1.0 \pm 0.13$ & $1.1 \pm 0.28$ & $0.4 \pm 0.10$ \\
\hline & S. microstachya var. bordensis & 547 & $0.50 \pm 0.17$ & $0.4 \pm 0.15$ & $0.20 \pm 0.35$ \\
\hline & S. gordejevii & 238 & $1.30 \pm 0.22$ & $0.6 \pm 0.11$ & $0.40 \pm 0.27$ \\
\hline & S. myrtilloides & 837 & $1.20 \pm 0.31$ & $0.7 \pm 0.13$ & $0.4 \pm 0.34$ \\
\hline & Betula fruticosa & 2417 & $1.0 \pm 0.14$ & $0.5 \pm 0.18$ & $0.3 \pm 0.10$ \\
\hline & Ribes diacanthum & 168 & $0.8 \pm 0.16$ & $0.6 \pm 0.23$ & $0.1 \pm 0.11$ \\
\hline & Caragana microphylla & 414 & $0.3 \pm 0.12$ & $0.4 \pm 0.23$ & $0.35 \pm 0.14$ \\
\hline & Spiraea aquilegifolia & 1038 & $0.6 \pm 0.15$ & $0.8 \pm 0.14$ & $0.6 \pm 0.12$ \\
\hline
\end{tabular}

\subsection{Data Analysis}

The pair-correlation function $\mathrm{g}(\mathrm{r})$ is a statistical method used to estimate the number of points within concentric rings at a distance $r$ rather than within a certain radius and is especially sensitive to small-scale effects $[43,44]$. There are two $g$ (r) functions, i.e., univariate and bivariate $g$ (r). In this study, the univariate $g(r)$ function was used to analyze the spatial distribution patterns within woody plants, and the bivariate $g(r)$ function to quantify the both intra- and interspecific spatial association among tree and shrub plants $[43,44]$.

Firstly, the univariate $g(r)$ function was used to analyze three tree categories (old trees, medium trees, and juvenile trees) and all shrub species. The null model of complete spatial randomness (CSR) as a null hypothesis was used for all the univariate analyses. Secondly, for the bivariate analyses, two cases were considered. One case was that the relationship between small and large trees was considered. Since large trees may impact the distribution pattern of small trees within their area of influence (competition), a bivariate $g$ function analysis was conducted for these two size classes using both the toroidal shift and the antecedent condition null model options [43]. This tests whether the patterns of distribution of small and large trees were generated by independent processes. The antecedent condition model tests whether one pattern (small trees) is influenced by a second 
pattern (large trees), assessing whether there are more (or fewer) small trees in the neighborhood of large trees than expected under a random distribution of small trees [43]. The second case concerns the interaction between trees and shrubs. Because the spatial distributions of plants in plots seem to be affected significantly by drought stress and habitat heterogeneity (e.g., soil patch and microtopography), we examined the spatial association between the two species with the independent null model [44].

All analyses were conducted with Programita software (2016). To assess the significance of the data by comparing them with the null model, $95 \%$ confidence intervals were obtained by running 199 Monte Carlo simulations [45].

\section{Results}

\subsection{Characteristics of the Temperate Savanna Ecosystem}

There were nine woody plant species, S. linearistipularis, S. microstachya var. bordensis, S. gordejevii, S. myrtilloides, B. fruticosa, C. microphylla, Spiraea aquilegifolia, R. diacanthum, and U. pumila, which were identified in the plot. The trees in the plot mainly grew as individual trees rather than in groups (Table 1).

U. pumila was the dominant tree species, with a coverage of $10-15 \%$ and a density of 56 trees/ha. The densities of old trees (DBH $\geq 20 \mathrm{~cm}$ ), medium trees $(5 \mathrm{~cm} \leq \mathrm{DBH}<20 \mathrm{~cm}$ ), and juvenile trees $(\mathrm{DBH}<5 \mathrm{~cm})$ were 30,10 , and 16 trees/ha, respectively. The tree heights of these three categories varied, i.e., old trees, medium trees, and juvenile trees had average heights of $8.4 \pm 0.94,5.3 \pm 0.93$, and $1.7 \pm 0.30 \mathrm{~m}$, respectively. Although the coverage of the shrub layer was only $8-15 \%$, eight shrub species were observed, and their density varied from 6.7 to 96.7 plants/ha; the shrubs were shorter than $0.3-1.3 \mathrm{~m}$ on average. These shrubs normally grew in clusters distributed in the canopy gaps among $U$. pumila trees.

The herbs were also unevenly distributed and were rarely found growing under the old trees. However, the coverage of the herb layer, 30-60\%, was greater than that of the tree and shrub layers. The herbs were also very diverse, with a total of 195 species from 40 families identified in our research plot, representing approximately $30 \%$ of the total number of higher plants observed in the Otindag Sandy Land $[18,39]$. The herbs mainly belonged to the Compositae (38 species), Gramineae (30 species), and Leguminosae (14 species) families.

\subsection{Spatial Distribution Patterns of U. pumila Trees-A Random Distribution of Old Trees and an Aggregated Distribution of Juvenile Trees}

As shown in Figure 2, U. pumila trees showed significant aggregation at the 0-7 $\mathrm{m}$ scale. However, their distribution patterns varied with tree size. The old $U$. pumila trees were randomly distributed at all scales $(0-50 \mathrm{~m})$; in contrast, the medium $U$. pumila trees $(5 \mathrm{~cm} \leq \mathrm{DBH}<20 \mathrm{~cm})$ exhibited significant aggregation at the $0-5 \mathrm{~m}$ scale, and juvenile trees $(\mathrm{DBH}<5 \mathrm{~cm})$ were significantly aggregated at the 0-9 m scale. However, all three tree categories were randomly distributed at other scales in the 25-ha permanent plot.

As shown in Figure 3, there were intraspecific relationships between the different DBH classes of $U$. pumila trees. There was a significant negative relationship between old trees and medium trees at the 2-10 m scale, but no obvious relationships between old trees and juvenile trees. On the other hand, there was a significantly positive relationship between medium trees and juvenile trees at the 2-12 $\mathrm{m}$ scale, but no significant relationship at any other scale.

\subsection{Aggregated Distribution of Shrubs at Specific Scales}

As shown in Figure 4, most shrub species exhibited spatial aggregation at small scales. For example, S. aquilegifolia, S. microstachya var. bordensis, S. gordejevii, and C. microphylla were significantly aggregated at scales of $0-6,1-7,0-2$, and 0-6 $\mathrm{m}$, respectively. However, they exhibited random distributions at other scales. S. myrtilloides and B. fruticosa exhibited similar distribution patterns; they were significantly 
aggregated only at scales of 2-4 and 2-5 m, respectively, and had random distributions at other scales. The exceptions to these findings were $S$. linearistipularis and $R$. diacanthum, which were randomly distributed at all scales. These results indicate that spatial aggregation at specific scales was common among most shrub species.

\subsection{Spatial Interactions of Woody Plants-Competition between Shrubs and Adult Trees and Mutualism between Dominant Shrub Species and Juvenile Trees}

As shown in Figure 5, there was a negative relationship between the presence of old trees and most shrub species. For example, there was significant negative relationship between old trees and some shrubs, e.g., B. fruticosa and S. aquilegifolia, at all scales $(0-50 \mathrm{~m})$. However, other shrubs had significant negative relationships with old trees only at certain scales-for example, S. myrtilloides, at the 10-50 m scales; S. linearistipularis, at the 10-20 m scales; S. gordejevii, at the 0-30 m scales; and C. microphylla, at the $0-25 \mathrm{~m}$ scales. In addition, there was a positive relationship between $R$. diacanthum and old trees at the 3-6 m scales. These results showed that there was a competitive relationship between most shrubs and the old trees.
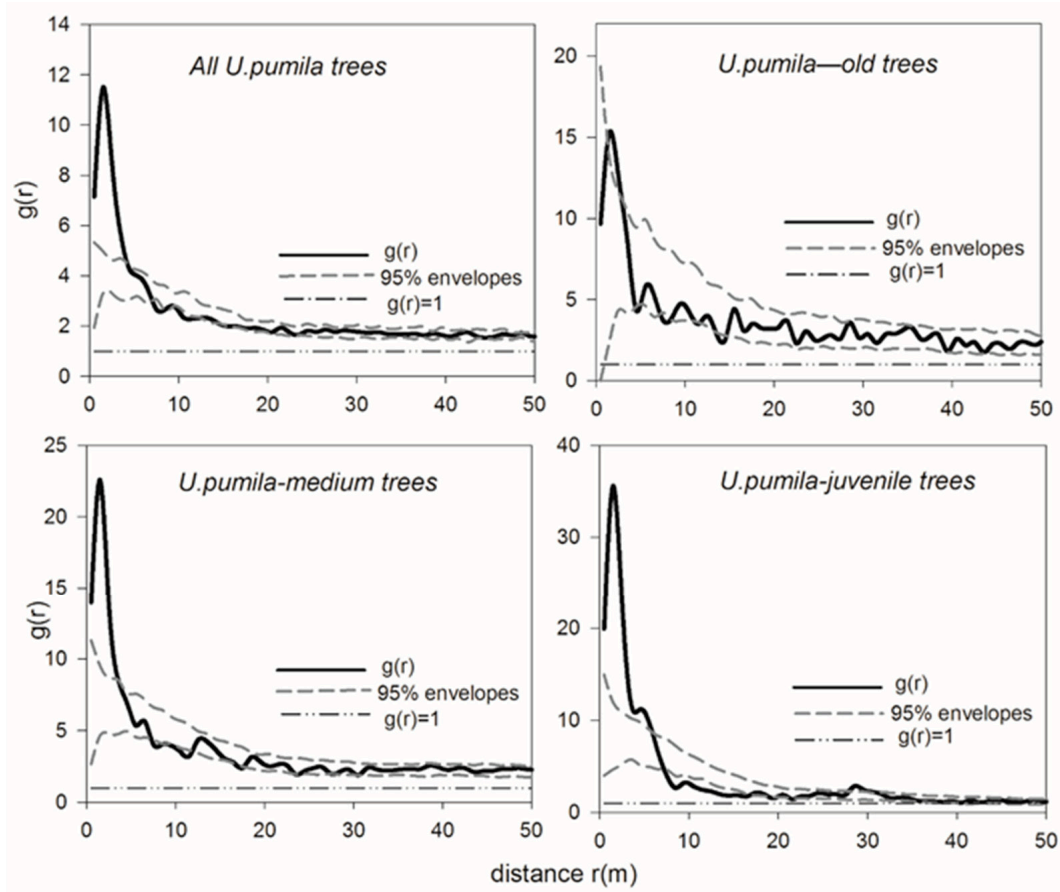

Figure 2. Univariate spatial patterns of the three $U$. pumila tree categories with the null model.
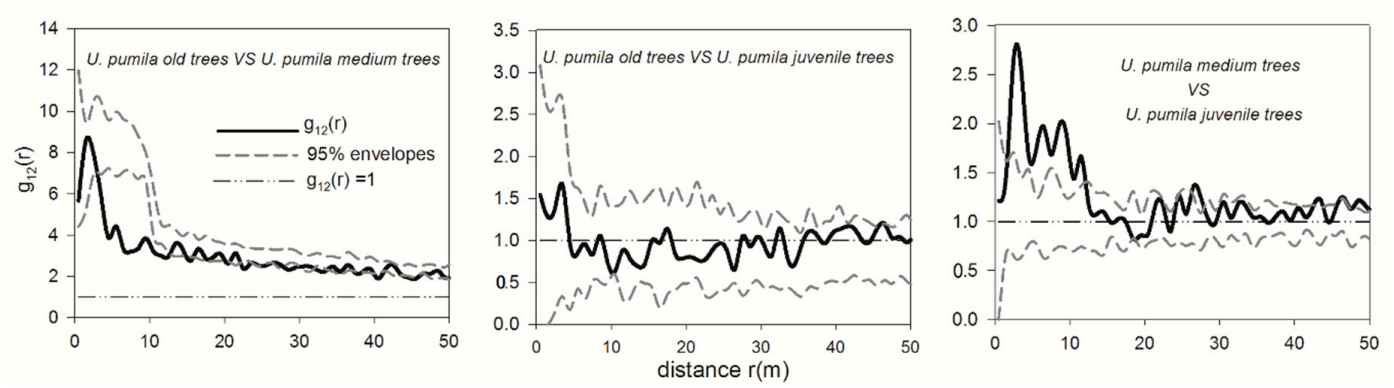

Figure 3. Bivariate spatial association between three $U$. pumila tree categories with both the toroidal shift and antecedent condition null models. 

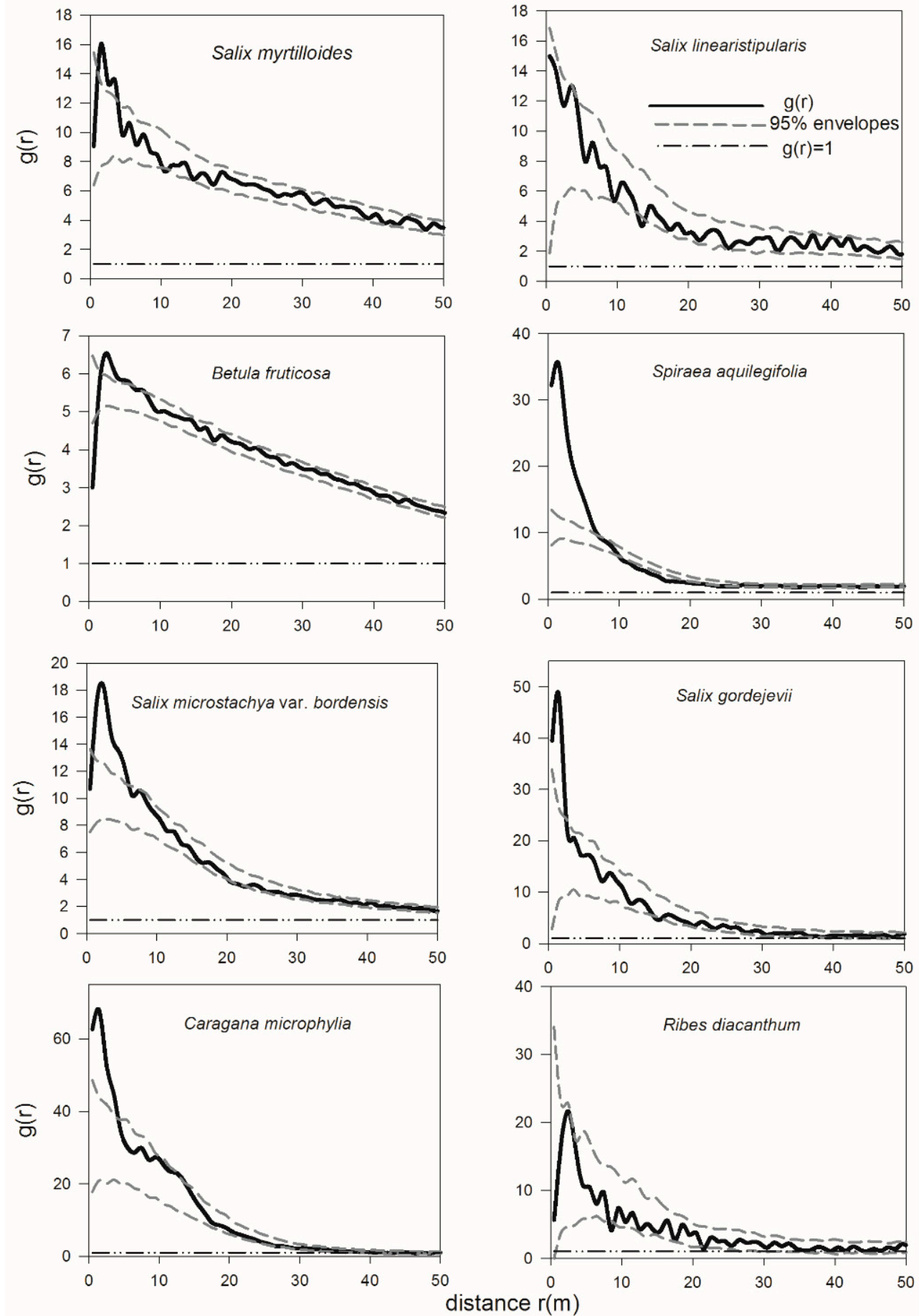

Figure 4. Univariate spatial patterns of shrub categories with the null model of complete spatial randomness. 

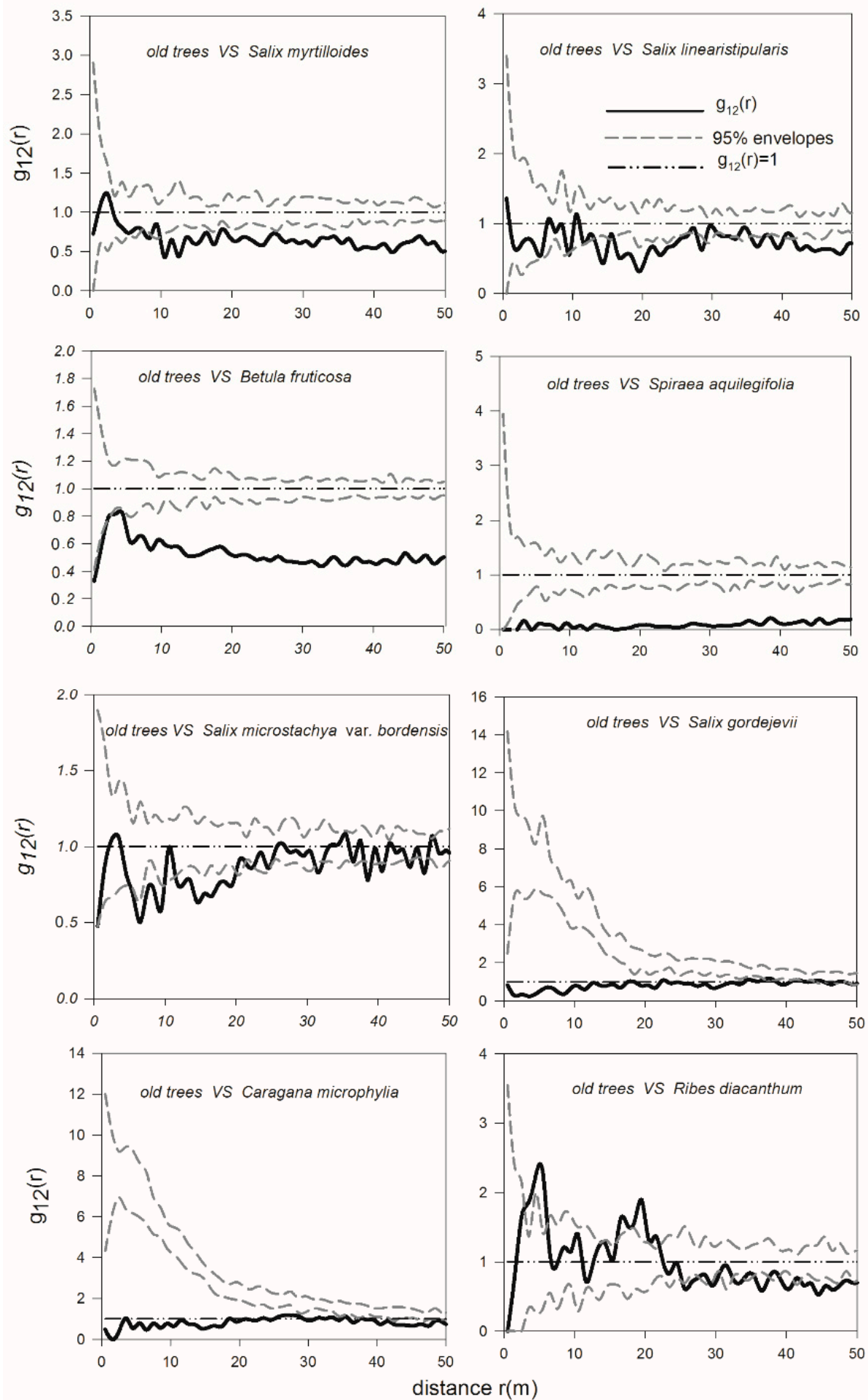

Figure 5. Bivariate spatial relationship between old $U$. pumila trees and shrubs with the independent null model. 
There were negative relationships between the medium trees and most shrub species (Figure 6). For example, the presence of the shrubs S. gordejevii, B. fruticosa, S. aquilegifolia, and S. microstachya var. bordensis was significantly negatively associated with medium trees at all scales $(0-50 \mathrm{~m})$. In addition, S. linearistipularis was significantly negatively correlated with medium trees only at the $15-50 \mathrm{~m}$ scales, and no obvious relationships were observed at other scales. For C. microphylla, S. gordejevii, and $R$. diacanthum, no obvious relationships with medium trees were observed. These results also showed that there was a competitive relationship between most shrubs and medium trees.
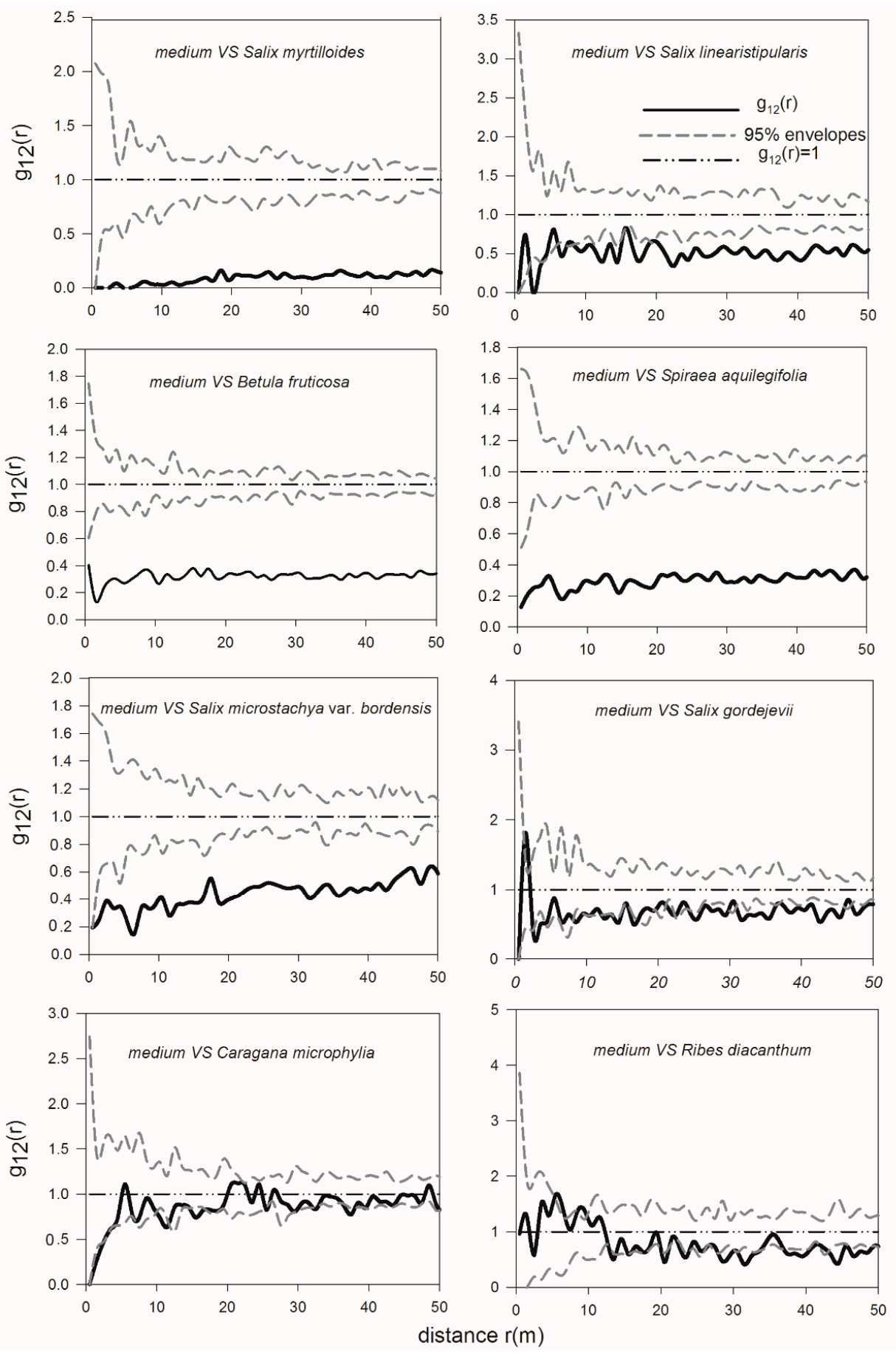

Figure 6. Bivariate spatial relationship between medium $U$. pumila trees and shrubs with the independent null model. 
However, there were positive relationships between juvenile trees and some shrub species (Figure 7). S. myrtilloides, S. aquilegifolia, S. microstachya var. bordensis, and C. microphylla showed significant positive interactions with juvenile trees at small scales (less than $10 \mathrm{~m}$ ). However, no other obvious relationships were observed between juvenile trees and the other shrub species.
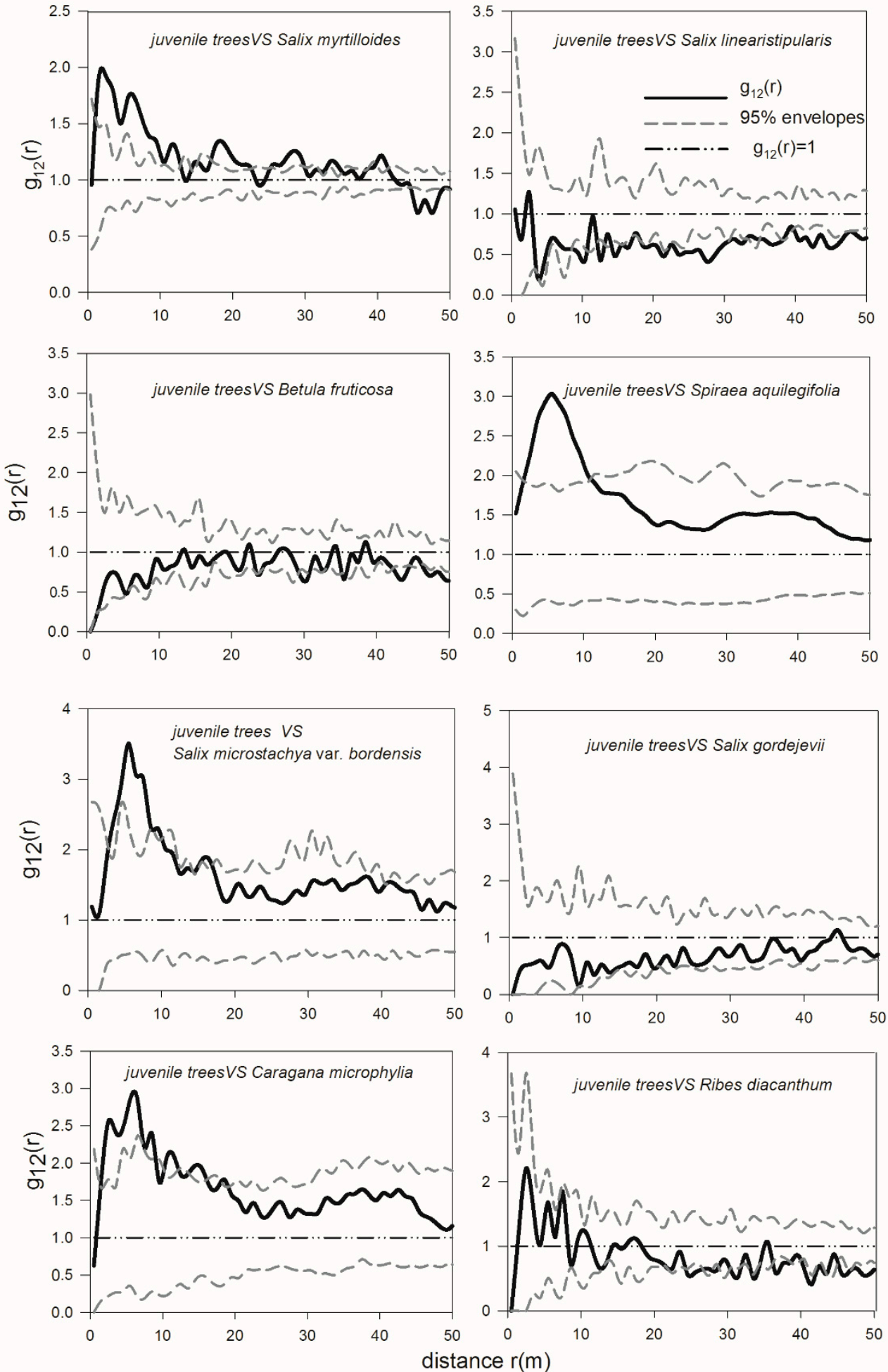

Figure 7. Bivariate spatial relationship between juvenile $U$. pumila trees and shrubs with the independent null model. 


\section{Discussion}

\subsection{Spatial Patterns of U. pumila Trees and Their Mechanism of Formation in the Temperate Savanna} -Like Ecosystem

From the viewpoint of ecological niche differentiation, the large crown breadth of adult U. pumila trees indicates a strong demand for a broad niche [46], and its random distribution indicates strong competition among U. pumila trees. U. pumila trees of the temperate savanna normally have a larger crown width $(6-12 \mathrm{~m})$ and deeper roots (10-20 $\mathrm{m}$ depth) than $U$. pumila trees in temperate forests (4-8 $\mathrm{m}$ crown width, 3-5 $\mathrm{m}$ root depth) [42]. In this study, the old U. pumila trees were randomly distributed at all scales. This indicates that $U$. pumila exhibits strong self-thinning due to the intense competition among individual trees [47]. In temperate forests, self-thinning normally occurs due to light competition $[48,49]$. However, in this study, light was not a limiting factor, as indicated by the large tree crowns. Thus, soil moisture can be deduced to be the key limiting factor that results in trees being randomly distributed far from each other through self-thinning [50]. This deduction can also be indirectly supported by the small amount and high variability of the annual precipitation in this area, which is typically 200-350 $\mathrm{mm} \mathrm{[37,38].} \mathrm{Drought} \mathrm{has} \mathrm{been} \mathrm{increasing} \mathrm{continuously} \mathrm{in} \mathrm{this} \mathrm{area} \mathrm{since}$ 1960, and the most severe drought in recorded history in this area occurred during 1999-2011 [51]. In addition, U. pumila seedlings often suffer from severe water stress during dry summers that is caused by repeated cycles of drying in the upper soil layers [52]. Wang et al. [53] noted that more than $90 \%$ of the current-year seedlings died in fenced plots because of their vulnerability to drought. Therefore, light limitation is generally replaced by increasing water stress in drought-modulated ecosystems, such as semiarid forests and temperate savanna [54].

\subsection{Spatial Interactions among Trees and Shrubs-Old U. pumila Trees Inhibit the Survival of Juvenile Trees and Shrubs}

In this study, a negative relationship between old $U$. pumila trees and juvenile trees was found, and significant competition between most shrub species and old $U$. pumila trees was also found. From these findings, we can conclude that the environment around old $U$. pumila trees is not suitable for the survival of juvenile trees or shrubs $[53,55]$. This further demonstrates that seedling regeneration in the U. pumila-dominated savanna-like ecosystem depends strongly on medium trees rather than on old trees. This situation is likely due to the influence of grazing. Historically, the U. pumila-dominated savanna-like ecosystem of the Otindag Sand Land was an important pasture source, providing a large amount of forage for livestock [51,56]. Although precipitation and soil moisture have been the main limiting factors affecting population regeneration of woody plants in arid and semiarid areas [57], grazing has become an important factor affecting population regeneration; long-term continuous heavy grazing has resulted in the destruction of topsoil and degradation of the rangeland [58]. In this savanna-like ecosystem, the area under the tree crown is usually occupied by resting livestock taking shelter from the summer heat and the intense ultraviolet radiation. Thus, the soil under the crown may be destroyed and become hardened due to the animals' trampling and reclining, and a "bare soil circle" will sometimes form under these trees [59]. This is similar to the phenomenon of piospheres caused by grazing. It was found by some studies that the soil moisture and nutrients in the piospheres are significantly lower than those in other areas; this may be the main reason for the change of vegetation composition and pattern, such as reduction in the density and production of forage, changes in the species composition of forage vegetation, shrub encroachment, and so on [59]. Some studies focus on the "bare soil circle" formed under these trees in this savanna-like ecosystem and also prove that the soil moisture and nutrients on the "bare soil circle" are lower than those outside the crown of elm [60]. These factors are unfavorable to the survival of any individual plant, including juvenile trees, shrubs, and grasses. Therefore, the disturbance of livestock caused by overgrazing may be one of the main reasons for the negative relationships between old $U$. pumila and juvenile trees and shrubs in this region. 
In contrast, medium trees exhibited a significant positive association with juveniles at smaller scales. This suggests that the environmental conditions, such as light availability and soil moisture, around medium trees are more favorable for juvenile trees than those around adult trees. Some studies also show that the soil nutrients (organic matter, total nitrogen, available phosphorus) and soil moisture under the crown of medium trees are significantly higher than those outside the crown, and there are better microenvironmental conditions (light, temperature, humidity, etc.) under the crown [60]. In addition, the disturbance of livestock to medium trees is less than that to old trees.

Different shrub species showed different spatial relationships with $U$. pumila in this study. There were positive relationships between juvenile trees and some shrub species, such as C. microphylla. This may be because the emergence of shrubs improves soil moisture and nutrient conditions [61,62], and C. microphylla surely can provide some fertilization of the area due to the symbiosis with Azotobacter spp. This demonstrates that some shrubs provide some fertilization to the area in which they grow, thereby providing a favorable environment for $U$. pumila seedling growth. These results also showed that there were mutualistic relationships between juvenile trees and the shrubs S. gordejevii and S. aquilegifolia; this might be because $S$. aquilegifolia and C. microphylla, as spiny shrubs, can provide shelter for elm seeding, such as holding back sand and reducing damage from livestock and wind, which would protect the juvenile $U$. pumila trees [63]. Our results were similar to those of Tölgyesi et al. [9], who also found that thorny shrubs were important for supporting the biodiversity of wooded rangelands as well as facilitating the regeneration of trees by acting as nurse species.

\subsection{The Development of the Original Tree-Dominated Temperate Savanna-Like Ecosystem after Shrub Encroachment}

U. pumila-dominated temperate savanna-like ecosystem, once widely distributed throughout the forest-steppe ecotone on the Mongolian Plateau, is a relatively stable woody-herbaceous complex ecosystem in Northern China. Unfortunately, by the late 1990s, only a few degraded relic stands remained as scattered and fragmented patches that showed apparent regeneration failure [64]. This degradation was mainly due to irrational human land use, such as overgrazing.

Many studies clearly showed the indicative significance of shrub encroachment, which mainly depends on different factors, such as the type of ecosystem, past management practices, the current level of biodiversity, climate change, etc. $[13,14]$. In this region, shrubs have occupied the grassland habitat. This encroachment has led to a decrease in grass coverage and a decline in pasture quality [51]. This change is likely to become more serious with the increase in grazing pressure and the impacts of global warming. These outcomes suggest that shrub encroachment is an indicator of savanna ecosystem degradation to some extent. On the other hand, in this study, shrub encroachment was shown to promote the survival and growth of juvenile trees to some extent, which is beneficial to the reestablishment of the $U$. pumila community. However, mutualism was not observed between most shrub species and medium $U$. pumila trees in this study. This lack of mutualism may have occurred because the seedlings under the shrubs had not yet developed into medium trees at the time of this study, because the seedlings were excluded by the shrubs before developing into medium trees, or because the older seedlings may have excluded the shrubs from the habitat. If the shrubs were excluded by the older seedlings, this suggests that the emergence of shrubs in this habitat is only a phase. Conversely, if the small trees were excluded, this would be catastrophic for the ecosystem, and it would be difficult for the ecosystem to return to its original state. To determine the exact causes of these phenomena, further experimental observation is greatly needed. Regardless, this study demonstrated that shrub encroachment in this area has resulted in changes in the composition and spatial pattern of the original tree-dominated savanna. 


\section{Conclusions}

In conclusion, shrub encroachment was observed in a temperate savanna-like ecosystem in Northern China, possibly as a result of both grazing and climate change. Shrub encroachment in this area has resulted in changes in the composition and spatial pattern of the original tree-dominated savanna. Due to severe damage to the $U$. pumila-dominated temperate savanna-like ecosystem, especially for woody vegetation, ecological degradation has occurred, such as decreasing temperate savanna-like area, loss of structural integrity, poor population regeneration, and changing spatial patterns. New management techniques and climate change mitigation practices should be implemented to replace the older, traditional management techniques and to prevent the original tree-dominated temperate savanna-like ecosystem from changing into a shrub-dominated temperate savanna-like ecosystem. A more scientific and effective management regime should be developed to maintain the stability and sustainability of this typical tree-dominated temperate savanna-like ecosystem currently and in the near future.

Author Contributions: Conceptualization, X.W., Z.S. and P.Y.; Methodology, X.Y.; Data Curation, X.W. and L.J.; Formal Analysis, X.W.; Writing-Original Draft Preparation, X.W.; Writing-Review and Editing, X.W. and P.Y; Supervision, Z.S. and Y.L. All authors have read and agreed to the published version of the manuscript.

Funding: This research was supported by the Special Foundation for National Science and Technology Basic Resource Investigation Program of China (2017FY101301), the National Key Research and Development Program of China (2016YFC0500801; 2016YFC0500804), the National Natural Science Foundation of China (31670715; $41471029 ; 41701249 ; 31200350)$.

Acknowledgments: We sincerely thank the local herder's family for providing their rangeland for this research. We also thank Wiegand for his generous provision of spatial analysis software.

Conflicts of Interest: The authors declare no conflict of interest.

\section{References}

1. Archer, S.R.; Andersen, E.M.; Predick, K.I.; Schwinning, S.; Woods, S.R. Woody Plant Encroachment: Causes and Consequences; Rangeland Systems; Springer: Cham, Switzerland, 2017; ISBN 978-3-319-46707-8.

2. Stevens, N.; Lehmann, C.E.R.; Murphy, B.P.; Durigan, G. Savanna woody encroachment is widespread across three continents. Glob. Chang. Biol. 2017, 23, 235-244. [CrossRef]

3. Naito, A.T.; Cairns, D.M. Patterns and processes of global shrub expansion. Prog. Phys. Geogr. 2011, 35, 423-442. [CrossRef]

4. Ravi, S.; D'Odorico, P.; Wang, L.; White, C.S.; Okin, G.S.; Macko, S.A.; Collins, S.L. Post-fire resource redistribution in desert grasslands: A possible negative feedback on land degradation. Ecosystems 2009, 12, 434-444. [CrossRef]

5. Ratajczak, Z.; Nippert, J.B.; Collins, S.L. Woody encroachment decreases diversity across North American grasslands and savannas. Ecology 2012, 93, 697-703. [CrossRef] [PubMed]

6. Grover, H.D.; Musick, H.B. Shrubland encroachment in southern new Mexico, USA.: An analysis of desertification processes in the american southwest. Clim. Chang. 1990, 17, 305-330. [CrossRef]

7. D'Odorico, P.; Okin, G.S.; Bestelmeyer, B.T. A synthetic review of feedbacks and drivers of shrub encroachment in arid grasslands. Ecohydrology 2012, 5, 520-530. [CrossRef]

8. Van Auken, O.W.; Bush, J. Invasion of Woody Legumes; Springer: Berlin/Heidelberg, Germany, 2013; p. 67.

9. Tölgyesi, C.; Bátori, Z.; Gallé, R.; Urák, I.; Hartel, T. Shrub encroachment under the trees diversifies the herb layer in a Romanian silvopastoral system. Rangel. Ecol. Manag. 2017, 71, 571-577. [CrossRef]

10. Tabares, X.; Zimmermann, H.; Dietze, E.; Ratzmann, G.; Herzschuh, U. Vegetation state changes in the course of shrub encroachment in an african savanna since about $1850 \mathrm{ce}$ and their potential drivers. Ecol. Evol. 2020, 10, 962-979. [CrossRef]

11. Li, Y.; Chen, J.; Cui, J.; Zhao, X.; Zhang, T. Nutrient resorption in caragana microphylla along a chronosequence of plantations: Implications for desertified land restoration in north china. Ecol. Eng. 2013, 53, $299-305$. [CrossRef]

12. Devine, A.P.; McDonald, R.A.; Quaife, T.; Maclean, I.M.D. Determinants of woody encroachment and cover in African savannas. Oecologia 2017, 183, 939-951. [CrossRef] 
13. Eldridge, D.J.; Bowker, M.A.; Maestre, F.T.; Roger, E.; Reynolds, J.F.; Whitford, W.G. Impacts of shrub encroachment on ecosystem structure and functioning: Towards a global synthesis. Ecol. Lett. 2011, 14, 709-722. [CrossRef] [PubMed]

14. Erdős, L.; Cserhalmi, D.; Bátori, Z.; Kiss, T.; Morschhauser, T.; Benyhe, B.; Dénes, A. Shrub encroachment in a wooded-steppe mosaic: Combining GIS methods with landscape historical analysis. Appl. Ecol. Environ. Res. 2013, 11, 371-384. [CrossRef]

15. Hilbig, W. The Vegetation of Mongolia; SPB Academic Publishing: Amsterdam, The Netherlands, 1995; $246 \mathrm{p}$.

16. Fang, J.; Wang, Z.; Tang, Z. Atlas of Woody Plants in China: Distribution and Climate; Springer: Berlin/Heidelberg, Germany, 2011; 2020p.

17. Fu, L.; Xin, Y. Elms of China. In The Elms: Breeding, Conservation, and Disease Management; Dunn, C.P., Ed.; Kluwer Academic Publishers: New York, NY, USA, 2000; 384p.

18. Zhang, X.S. Vegetation of China and Its Geographic Patterns; Geological publishing House: Beijing, China, 2007; 1175p.

19. Zhao, H.-L.; Zhou, R.-L.; Su, Y.-Z.; Zhang, H.; Zhao, L.-Y.; Drake, S. Shrub facilitation of desert land restoration in the Horqin Sand Land of Inner Mongolia. Ecol. Eng. 2007, 31, 1-8. [CrossRef]

20. Wigley, B.J.; Bond, W.J.; Hoffman, M.T. Thicket expansion in a south african savanna under divergent land use: Local vs. global drivers? Glob. Chang. Biol. 2010, 16, 964-976. [CrossRef]

21. Venter, Z.S.; Cramer, M.D.; Hawkins, H.-J. Drivers of woody plant encroachment over africa. Nat. Commun. 2018, 9, 1-7. [CrossRef]

22. O'Connor, R.C.; Taylor, J.H.; Nippert, J.B. Browsing and fire decreases dominance of a resprouting shrub in woody encroached grassland. Ecology 2020, 101, e02935. [CrossRef]

23. Liu, F.; Wu, X.; Bai, E.; Boutton, T.W.; Archer, S.R. Spatial scaling of ecosystem $\mathrm{c}$ and $\mathrm{n}$ in a subtropical savanna landscape. Glob. Chang. Biol. 2010, 16, 2213-2223. [CrossRef]

24. Nie, W.; Yuan, Y.; Kepner, W.; Erickson, C.; Jackson, M. Hydrological impacts of mesquite encroachment in the upper san pedro watershed. J. Arid Environ. 2012, 82, 147-155. [CrossRef]

25. Li, L.; He, W.; Changcun, L.; Deli, W. Vegetation and community changes of elm (ulmus pumila) woodlands in northeastern china in 1983-2011. Chin. Geogr. Sci. 2013, 23, 321-330. [CrossRef]

26. Li, Z.; Wang, X.-J.; Liu, G.-H.; Niu, H.-L.; Zhen, P. Dynamics, patterns and structure of major population in ulmus pumila var. sabulosa sparse forest in hunshandake sandland. J. Desert Res. 2009, 29, 508-513. (In Chinese)

27. Chen, L.; Li, H.; Zhang, P.; Zhao, X.; Zhou, L.; Liu, T.; Hu, H.; Bai, Y.; Shen, H.; Fang, J. Shrub-encroached grassland: A new vegetation type. Chin. J. Nat. 2014, 36, 391-396. (In Chinese)

28. Su, H.; Li, Y.; Liu, W.; Xu, H.; Sun, O.J. Changes in water use with growth in Ulmus pumila in semiarid sandy land of northern China. Trees 2014, 28, 41-52. [CrossRef]

29. Dale, M.R.T. Spatial Pattern Analysis in Plant. Ecology; Cambridge University Press: Cambridge, UK, 1999; 340p.

30. Nathan, R. Long distance dispersal of plants. Science 2006, 313, 786-788. [CrossRef] [PubMed]

31. Druckenbrod, D.L.; Shugart, H.H.; Davies, I. Spatial pattern and process in forest stands with in the Virginia piedmont. J. Veg. Sci. 2005, 16, 37-48. [CrossRef]

32. Wiegand, T.; Moloney, K.A. Handbook of Spatial Point-Pattern Analysis in Ecology; CRC Press: Boca Raton, FL, USA, 2014; 481p.

33. He, F.; Legendre, P.; La Frankie, J.V. Distribution patterns of tree species in a Malaysian tropical rain forest. J. Veg. Sci. 1997, 8, 105-114.

34. Condit, R.; Ashton, P.S.; Baker, P.; Bunyavejchewin, S.; Gunatilleke, S.; Gunatilleke, N.; Hubbell, S.P.; Foster, R.B.; Itoh, A.; LaFrankie, J.V.; et al. Spatial patterns in the distribution of tropical tree species. Science 2000, 288, 1414-1418. [CrossRef]

35. Wang, Y.; Yang, X.; Shi, Z. The formation of the patterns of desert shrub communities on the western Ordos Plateau, China: The roles of seed dispersal and sand burial. PLoS ONE 2013, 8, e69970. [CrossRef]

36. Wu, B.; Yang, H. Spatial Patterns and Natural Recruitment of Native Shrubs in a Semi-arid Sandy Land. PLoS ONE 2013, 8, e58331. [CrossRef]

37. Chun, X.; Yong, M.; Liu, J.; Liang, W. Monitoring land cover change and its dynamic mechanism on the qehan lake basin, inner mongolia, north china, during 1977-2013. Environ. Monit. Asses. 2018, 190, 205. [CrossRef] 
38. Bai, Y.F.; Wu, J.G.; Xing, Q.; Pan, Q.M.; Huang, J.H.; Yang, D.L.; Han, X.G. Primary production and rain use efficiency across a precipitation gradient on the Mongolia plateau. Ecology 2008, 89, 2140-2153. [CrossRef]

39. Editorial Committee of Flora of China. Flora of China, Revised ed.; Scientific Press: Beijing, China, 2013.

40. Li, S.-L.; Yu, F.-H.; Werger, M.J.A.; Dong, M.; Ramula, S.; Zuidema, P.A. Understanding the effects of a new grazing policy: The impact of seasonal grazing on shrub demography in the inner mongolian steppe. J. Appl. Ecol. 2013, 50, 1377-1386. [CrossRef]

41. Condit, R. Research in large, long-term tropical forest plots. Trends Ecol. Evol. 1995, 10, 18-22. [CrossRef]

42. Yu, P. Restoring Degraded Ecosystem in Hunshandak Sand Land through Nature Reserve. Ph.D. Thesis, Chinese Academy of Science, Beijing, China, 2005; 114p.

43. Stoyan, D.; Stoyan, H. Improving ratio estimators of second order point process characteristics. Scand. J. Stat. 2000, 27, 641-656. [CrossRef]

44. Wiegand, T.; Moloney, K.A. Rings, circles and null-models for point pattern analysis in ecology. Oikos 2004, 104, 209-229. [CrossRef]

45. Illian, J.; Penttinen, A.; Stoyan, H.; Stoyan, D. (Eds.) Statistical Analysis and Modelling of Spatial Point Patterns; John Wiley \& Sons: Chichester, UK, 2008; 560p.

46. Kim, D.; Campbell, J.J.N. Effects of tree size, shade tolerance, and spatial pattern on the mortality of woody plants in a seminatural forest in central kentucky. Prof. Geogr. 2016, 68, 436-450. [CrossRef]

47. Skarpe, C. Spatial patterns and dynamics of woody vegetation in an arid savanna. J. Veg. Sci. 2010, 2, 565-572. [CrossRef]

48. Landry, S.; St-Laurent, M.H.; Nelson, P.R.; Pelletier, G.; Villard, M.A. Canopy cover estimation from landsat images: Understory impact on top-of-canopy reflectance in a northern hardwood forest. Can. J. Remote Sens. 2018, 44, 435-446. [CrossRef]

49. Sitch, S.; Smith, B.; Prentice, I.C.; Arneth, A.; Bondeau, A.; Cramer, W.; Kaplan, J.O.; Levis, S.; Lucht, W.; Sykes, M.T.; et al. Evaluation of ecosystem dynamics, plant geography and terrestrial carbon cycling in the lpj dynamic global vegetation model. Glob. Chang. Biol. 2003, 9, 161-185. [CrossRef]

50. Hartmann, H. Will a 385 million year-struggle for light become a struggle for water and for carbon?-How trees may cope with more frequent climate change-type drought events. Glob. Chang. Biol. 2011, 17, 642-655. [CrossRef]

51. Zhang, Z.; Zhang, B.; Zhang, X.; Yang, X.; Shi, Z.; Liu, Y. Grazing altered the pattern of woody plants and shrub encroachment in a temperate savanna ecosystem. Int. J. Environ. Res. Public Health 2019, 16, 330. [CrossRef]

52. Guo, K.; Liu, H. A comparative researches on the development of elm seedlings in four habitats in the Otindag Sandland, Inner Mongolia, China. Acta Ecol. Sin. 2004, 24, 2024-2028. (In Chinese)

53. Wang, X.; Hu, C.; Li, G.; Zuo, H. Analysis of the factors affecting seed disperal and seedling survival rate of Ulmus pumila in the Otindag sandy land. Arid Zone Res. 2011, 28, 542-547. (In Chinese)

54. Dai, J.; Liu, H.; Wang, Y.; Guo, Q.; Hu, T.; Quine, T.; Green, S.; Hartmann, H.; Xu, C.; Liu, X.; et al. Drought-modulated allometric patterns of trees in semi-arid forests. Commun. Biol. 2020, 405, 1-8. [CrossRef] [PubMed]

55. Wang, X.; Zhang, B.; Zhang, K.; Zhou, J.; Ahmad, B. The spatial pattern and interactions of woody plants on the temperate savanna of inner mongolia, china: The effects of alternating seasonal grazing-mowing regimes. PLoS ONE 2015, 10, e0133277. [CrossRef]

56. Qi, J.; Chen, J.; Wan, S.; Ai, L. Understanding the coupled natural and human systems in dryland east asia. Environ. Res. Lett. 2012, 7, 15202-15207. [CrossRef]

57. Priyadarshini, K.V.R.; Prins, H.H.T.; De Bie, S.; Heitkönig, I.M.; Woodborne, S.; Gort, G.; Kirkman, K.P.; Ludwig, F.; Dawson, T.E.; De Kroon, H. Seasonality of hydraulic redistribution by trees to grasses and changes in their water-source use that change tree-grass interactions. Ecohydrology 2015, 9, 217-228. [CrossRef]

58. Stumpp, M.; Wesche, K.; Retzer, V.; Miehe, G. Impact of grazing livestock and distance from water source on soil fertility in southern mongolia. Mt. Res. Dev. 2005, 25, 244-251. [CrossRef]

59. Anthony, E.; Bernard, B.; Henry, M.M.; Paul, N. Piosphere syndrome and rangeland degradation in Karamoja sub-region, Uganda. Resour. Environ. 2015, 5, 73-89. [CrossRef]

60. Zhang, Z. Spatial Distribution of Vegetation and Soil in Temperate Savanna Ecosystem, Inner Mongolia. Ph.D. Thesis, Chinese Academy Forestry, Beijing, China, 2017; 137p. 
61. Dohn, J.; Augustine, D.J.; Hanan, N.P.; Ratnam, J.; Sankaran, M. Spatial vegetation patterns and neighborhood competition among woody plants in an east african savanna. Ecology 2016, 98, 478. [CrossRef]

62. Mckinley, D.C.; Blair, J.M. Woody plant encroachment by juniperus virginiana in a mesic native grassland promotes rapid carbon and nitrogen accrual. Ecosystems 2008, 11, 454-468. [CrossRef]

63. Schlesinger, W.H.; Raikes, J.A.; Hartley, A.E.; Cross, A.F. On the spatial pattern of soil nutrients in desert ecosystems. Ecology 1996, 77, 364-374. [CrossRef]

64. Dulamsuren, C.; Hauck, M.; Nyambayar, S. Establishment of Ulmus pumila seedlings on steppe slopes of the northern Mongolian mountain taiga. Acta Oecol. 2009, 35, 563-572. [CrossRef]

Publisher's Note: MDPI stays neutral with regard to jurisdictional claims in published maps and institutional affiliations.

(C) 2020 by the authors. Licensee MDPI, Basel, Switzerland. This article is an open access article distributed under the terms and conditions of the Creative Commons Attribution (CC BY) license (http://creativecommons.org/licenses/by/4.0/). 